\author{
Available online at https://www.rjtl.org \\ Volume: 1, Issue: 2, 40-43, 2020 \\ ISSN: 2708-3632 \\ DOI: https://doi.org/10.46590/rjtl.2020.010201
}

\title{
A Study on Antimicrobial Activity of Sericin on Cotton Fabric
}

\author{
K.V.Arunkumar ${ }^{1}$, K.Gomathi ${ }^{1}$, A.Deepika Priya ${ }^{1}$ \\ Assistant Professor, Department of Costume Design and Fashion, \\ Kongu Arts and Science College (Autonomous), Erode, Tamilnadu, India
}

Paper History

Received : July 2020

Accepted : August 2020

Published : August 2020

Corresponding Author

K.V.Arunkumar

kvaruncdf@gmail.com

\begin{abstract}
In the manufacturing of silk in the dried cocoons of a silkworm, fibroin is separated from sericin by a degumming process. The sericin is mostly discarded in the wastewater. The recovery of sericin not only reduces the environmental impact of silk manufacturing but a significant economic and social benefit could be realized from the recovery and recycling of sericin protein. Sericin has been studied as one of the new resources for textile and non-textile materials. It has properties like antioxidation, antibacterial, UV resistant, absorb and release of moisture, etc. Sericin has a good effect on wound healing, no toxicity, and low inflammatory reaction. Hence the present investigation aims to improve the antimicrobial activity of cotton fabric through the process of sericin finish.
\end{abstract}

Keywords: Antimicrobial, Cotton, Sericin, Silk

Citation: K.V.Arunkumar, K.Gomathi, A.Deepika Priya, A Study on Antimicrobial Activity of Sericin on Cotton Fabric, Research Journal of Textile and Leather, 1(2), 40-43, 2020.

\section{INTRODUCTION}

The Indian textile industry is one of the largest in the world with a massive raw material and textile manufacturing base. Our economy is largely dependent on textile manufacturing and trade in addition to other major industries. Many apparel products are made of cotton because their porous hydrophilic structure offers comfort in wear. However, the ability of cotton textiles to retain moisture, oxygen, and nutrients results in an ideal medium to accommodate microbes.

These microbes have many negative effects such as the generation of unpleasant odours, stains, decolourisation of the material, and a decrease in fabric mechanical strength. Hence, the quest for efficient, non-toxic, durable, and cost-effective antimicrobial finishing of textile materials is becoming increasingly intense, resulting in the progressive expansion of the production of antimicrobial textile materials.

The silk is composed of two important proteins namely fibroin and sericin. The central fibroin core is coated with a covering of sericin. The silk protein sericin, which is derived from silkworm cocoons, has been recently investigated by many researchers for possible new applications in the biomedical field. It has been reported that sericin has high moisture absorbing, antimicrobial, and UV protection properties. Suitably tailored sericin is used as a textile finish to improve moisture, UV absorption, and antimicrobial properties of treated fabrics. The present study aims to develop natural antimicrobial finish from silk sericin on cotton fabric

\section{MATERIAL AND METHODS}

\subsection{Selection of Fabric}

The superiority of cotton is due to easy availability, comfort during wear, and excellent wash properties. Because of its inherent properties, it can hold an important position despite the regenerated synthetic manmade fibers. Based on the desirable properties of cotton fabric the investigator has chosen $100 \%$ cotton fabric for the study.

\subsection{Pretreatment Method}

Pretreatment is the first and very important step in the textile process, the pretreatment processes of cotton fabric were done as follows

\subsubsection{Desizing}

The very first operation of wet processing of the cotton fabric is desizing, it is generally used to remove the added size. The pretreatment is done on grey fabric is to remove the starch from the fabric which is applied to the warp yarns during the weaving process.

The following parameters were considered for desizing of cotton fabric 


$\begin{array}{lll}\text { Hydrochloric acid } & - & 15 \mathrm{ml} / \text { litre } \\ \text { Temperature } & - & 50^{\circ} \mathrm{C} \\ \text { Time } & - & 2 \text { hours }\end{array}$

\subsubsection{Scouring}

Scouring is the pretreatment process of wet processing technology. Before dying or printing of cotton materials must pass the scouring process. Scouring is the process that removes non-cellulose impurities adhering to the fabric.

The cotton fabric was treated with $4 \%$ sodium hydroxide, $3 \%$ sodium silicate, and $1 \%$ soap solution with a liquor ratio of 1:30 and it is boiled for 2 hours at $90^{\circ} \mathrm{C}$ and then the fabric was rinsed thoroughly and dried.

\subsubsection{Bleaching}

Bleaching was given to eliminate nature and artificial impurities from fabric to obtain clean whiteness for further finishing processes such as dyeing or printing. Hydrogen peroxide was used as a bleaching agent; it is the safest bleach which gives a softer effect with minimum loss in weight. The cotton fabric was treated with magnesium sulphate $6.5 \%$, tetrasodium pyrosulphate $2.5 \%$, sodium hydroxide $8 \%$, hydrogen peroxide $3 \%$, wetting agent $1 \mathrm{ml}$, with liquor ratio of $1: 20$ and it is boiled at a temperature of $800 \mathrm{c}$ for 2 hours then the fabric rinsed and dried.

\subsection{Selection of Finish}

Antimicrobial finishes are used in textiles to control algae, bacteria, mould, mildew, yeast and to control problems like fabric staining, rotting, unpleasant odours, and health concerns. Hence the present investigation was done to develop natural antimicrobial finish from silk sericin for textile application.

\subsection{Collection of Silk Degummed Water}

Silk degummed water was collected from Padiur Sarvodhaya Sangam, Padiur at free of cost, and the collected water was stored in a cold room.

\subsection{Crude Sericin Extraction Methods}

The sericin was extracted by the following methods.

\subsubsection{Direct Sunlight Method}

Silk degummed water was poured into plates and kept in direct sunlight. Water was evaporated and the crude sericin was dried into a powder. Powdered material was scrapped out and stored in the refrigerator until analysis

\subsubsection{Centrifugation of Degummed Water}

The 1.5 litres of silk degummed water was centrifuged at $7000 \mathrm{rpm}$ for about 15 minutes. Then the pellet and supernatant were separated.

\subsubsection{Centrifugation with Direct Sunlight Method}

Centrifuged silk degummed water was poured in plates in a thin layer and kept in daylight. Water was evaporated and the crude sericin was settled down in the plate and scraped out and stored in the refrigerator until analysis.

\subsubsection{Concentration of Sericin with Heating Mantle Method}

$1000 \mathrm{ml}$ of centrifuged silk degummed water was evaporated in a heating mantle to about $1 / 6$ th of the original volume $(150 \mathrm{ml})$. Then the concentrated sericin was stored in a refrigerator until analysis.

\subsection{Antimicrobial Activity of Crude Sericin}

\subsubsection{Antimicrobial Test}

The Kirby - Bauer method is a standard antimicrobial susceptibility procedure in which the culture is inoculated on the surface of Muller-Hinton agar followed by the addition of antibiotic-impregnated on to the agar medium surface, establishing a concentration gradient. Inhibition of microbial growth is indicated by a clear zone formation around the wells. The zone gradient is established by the diffusion of antibiotics into the agar. The sensitivity of the best medium to use given microorganism depends on the specific antibiotic.

\subsubsection{Test Organism Used}

- Pseudomonas aeroginosa

- Salmonella typhimurium

- Bacillus subtilis

\subsubsection{Antimicrobial Test Procedure}

Muller-Hinton agar was prepared and its $\mathrm{pH}$ is adjusted to 7.4. The media was autoclaved under standard conditions and $20 \mathrm{ml}$ of the media was poured to each sterile Petri plates.

One drop of test organisms was spread on the Petri plate. $20 \mu 1$ extracts sericin was placed into each Petri plate with equal distance and the plates were incubated at $37^{\circ} \mathrm{C}$ for 24 hours. After incubation, the zone of inhibition on the plates was observed. Zone diameter was measured and the sensitivity of each organism was evaluated.

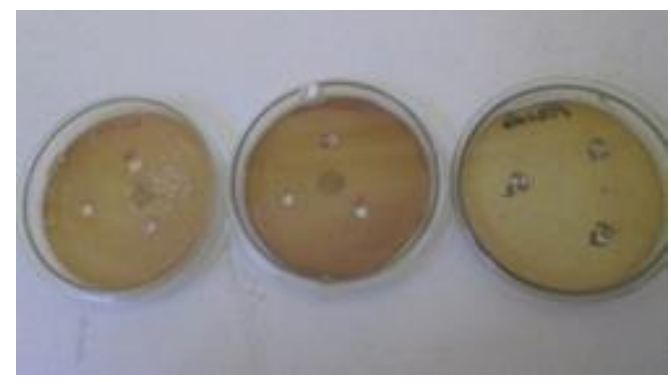

Figure 1. 


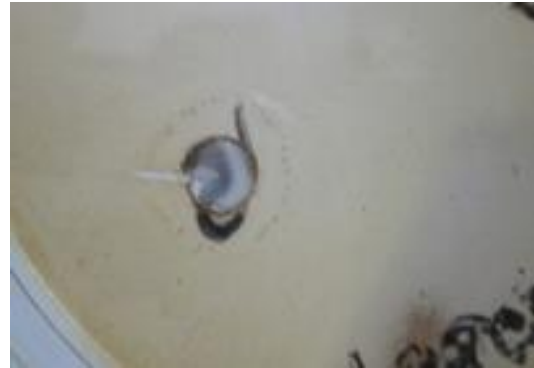

Figure 2.

\subsubsection{Antimicrobial Finish by Exhaustion Method}

The bleached cotton samples were placed in three beakers that each contains a 1:20 ratio of different extracted sericin solution at $80^{\circ} \mathrm{C}$ for $15 \mathrm{~min}$, with stirring, after that the treated samples were taken out from the beaker and dried in the air.

\subsubsection{Nomenclature of Sample}

Table 1. Nomenclature of Sample

\begin{tabular}{lll}
\hline S.No & Code & Samples \\
\hline 1 & UF & Untreated Fabric \\
2 & CS & $\begin{array}{l}\text { Crude Sericin (sundried) } \\
\text { Centrifuged Sericin } \\
\text { (sundried) }\end{array}$ \\
3 & CES & $\begin{array}{l}\text { Concentrated sericin } \\
\text { (Heating mantle) }\end{array}$ \\
\hline
\end{tabular}

\section{RESULTS AND DISCUSSION}

\subsection{Analysis of Antimicrobial Activity of Crude Sericin}

Agar diffusion test for extracted sericin is shown in table 2.

Table 2. Antimicrobial activity of crude sericin

\begin{tabular}{|c|c|c|c|}
\hline \multirow[b]{2}{*}{ Sample } & \multicolumn{3}{|c|}{ Zone of Inhibition (mm) } \\
\hline & $\begin{array}{l}\text { Pseudomonas } \\
\text { aeroginosa }\end{array}$ & $\begin{array}{l}\text { Salmonella } \\
\text { typhimurium }\end{array}$ & $\begin{array}{l}\text { Bacillus } \\
\text { subtilis }\end{array}$ \\
\hline $\mathrm{CS}$ & - & - & 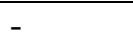 \\
\hline CES & - & - & - \\
\hline COS & $10 \mathrm{~m}$ & $15 \mathrm{~m}$ & - \\
\hline
\end{tabular}

-: No zone of inhibition

From table 2, it is noted that the sample COS has more antimicrobial activity against Pseudomonas and Salmonella.

\subsection{Analysis of Fabric Weight}

Table 3.Fabric Weight

\begin{tabular}{llll}
\hline Samples & $\begin{array}{l}\text { Mean in } \\
\text { GSM }\end{array}$ & $\begin{array}{l}\text { Loss or } \\
\text { Gain }\end{array}$ & $\begin{array}{l}\text { Percentage } \\
\text { change }\end{array}$ \\
\hline UF & 142 & - & - \\
CS & 159.8 & 17.8 & 11 \\
CES & 150 & 8 & 5.3 \\
COS & 160.6 & 18.6 & 11.5
\end{tabular}

Table 3. shows that the fabric weight has increased when compared to the original sample.

\subsection{Analysis of Fabric Thickness}

Table 4. Fabric Thickness

\begin{tabular}{llll}
\hline Samples & $\begin{array}{l}\text { Mean } \\
\text { thickness } \\
\text { mm }\end{array}$ & $\begin{array}{l}\text { Loss or } \\
\text { Gain }\end{array}$ & $\begin{array}{l}\text { Percentage } \\
\text { change }\end{array}$ \\
\hline UF & 0.55 & - & - \\
CS & 0.56 & 0.01 & 1.7 \\
CES & 0.57 & 0.02 & 3.5 \\
COS & 0.56 & 0.01 & 1.7 \\
\hline
\end{tabular}

From table 4. it is clear that there was a minimum difference in the fabric thickness of all finished samples.

\subsection{Analysis of Pilling Resistance}

Table 5. Pilling Resistance

\begin{tabular}{lll}
\hline Samples & $\begin{array}{l}\text { Average No of pills } \\
\text { per Sample }\end{array}$ & Rate of pilling \\
\hline UF & 82 & 6 \\
CS & 79 & 6 \\
CES & 78 & 6 \\
COS & 76 & 6 \\
\hline
\end{tabular}

From the above table 5. it is clear that the pilling resistance is found to be better in COS samples when compared to untreated fabric.

\subsection{Analysis of Abrasion Resistance}

Table 6. Abrasion resistance

\begin{tabular}{llll}
\hline Samples & $\begin{array}{l}\text { Mean in } \\
\text { Mg Ms }\end{array}$ & Loss or Gain & $\begin{array}{l}\text { Percentage } \\
\text { change }\end{array}$ \\
\hline UF & 0.027 & - & - \\
CS & 0.006 & 0.021 & 77.7 \\
CES & 0.009 & 0.018 & 66.6 \\
COS & 0.003 & 0.024 & 88.8 \\
\hline
\end{tabular}

The above table 6 . represents that the abrasion resistance is found to be greater in the sample COS. All the finished samples show better abrasion resistance than the unfinished sample.

\section{CONCLUSIONS}

The textile industry is the largest in terms of value, production, and also in hazardus generation. With the increasingly important requirement for textile manufactures to reduce pollution in a textile product, the recovery of sericin not only reduces the environmental impact of silk manufacturing but a significant economic and social benefit could be realized from the recovery and recycling of sericin protein. From the study, it is concluded that concentrated sericin has good antimicrobial against Pseudomonas aeroginosa and Salmonella typhimurium. Hence the investigator recommends, sericin finished fabrics for health care products like Bandage gauze, surgical clothes, baby diapers, sanitary napkins, and wipes. 


\section{REFERENCES}

\section{References}

[1] Agrawal.P, Bhushan.S, "Preparation of sericin nanoparticles from a waste of silk industry", International Journal of Science Research, 1(3), Pp. 116-120. 2012.

[2] Aramwit.P, Siritientong.T, and Srichana.T, "Potential applications of silk sericin, a natural protein from textile industry byproducts", Waste Management \& Research, 30(3), Pp. 217-224. 2012

[3] Arunkumar K.V, "Degumming of Silk Yarn using Various Soap Method" International Journal of Multidisciplinary Research Centre, 2(8), Pp 11-17. 2016.

[4] Padol R.A, Jayakumar.K, Mohan.K, Manochaya S, "Natural biomaterial silk and silk proteins: Applications in tissue repair", International Journal of Materials and Biomaterials Applications 2(4), Pp: 19-24. 2012. 